\title{
Immunopathological Roles of Cytokines, Chemokines, Signaling Molecules, and Pattern-Recognition Receptors in Systemic Lupus Erythematosus
}

\author{
Shui-Lian Yu, ${ }^{1}$ Woon-Pang Kuan, ${ }^{2}$ Chun-Kwok Wong, ${ }^{3}$ Edmund K. Li, ${ }^{1}$ and Lai-Shan Tam ${ }^{1}$ \\ ${ }^{1}$ Department of Medicine and Therapeutics, Prince of Wales Hospital, The Chinese University of Hong Kong, \\ 30-32 Ngan Shing Street, Shatin, Hong Kong \\ ${ }^{2}$ Department of Rheumatology, Hospital Selayang, Lebuhraya Selayang-Kepong, 68100 Batu Caves, Malaysia \\ ${ }^{3}$ Department of Chemical Pathology, Prince of Wales Hospital, The Chinese University of Hong Kong, \\ 30-32 Ngan Shing Street, Shatin, Hong Kong \\ Correspondence should be addressed to Lai-Shan Tam, lstam@cuhk.edu.hk
}

Received 12 July 2011; Accepted 11 October 2011

Academic Editor: Philip Alex

Copyright (c) 2012 Shui-Lian Yu et al. This is an open access article distributed under the Creative Commons Attribution License, which permits unrestricted use, distribution, and reproduction in any medium, provided the original work is properly cited.

Systemic lupus erythematosus (SLE) is an autoimmune disease with unknown etiology affecting more than one million individuals each year. It is characterized by B- and T-cell hyperactivity and by defects in the clearance of apoptotic cells and immune complexes. Understanding the complex process involved and the interaction between various cytokines, chemokines, signaling molecules, and pattern-recognition receptors (PRRs) in the immune pathways will provide valuable information on the development of novel therapeutic targets for treating SLE. In this paper, we review the immunopathological roles of novel cytokines, chemokines, signaling molecules, PRRs, and their interactions in immunoregulatory networks and suggest how their disturbances may implicate pathological conditions in SLE.

\section{Introduction}

Systemic lupus erythematosus (SLE) is a prototypic systemic autoimmune disease which is characterized by a loss of tolerance to nuclear antigens and various immunological abnormalities, including dysregulated activation of both $\mathrm{T}$ and $\mathrm{B}$ lymphocytes and subsequent polyclonal activation of circulating B lymphocytes which produces a large quantity of autoreactive antibodies and the formation of immune complexes causing tissue and organ damage [1]. This is a complex process involved interaction between various cytokines, chemokines, signaling molecules, and pattern-recognition receptors (PRRs) in the immune pathways. With the advent of new and advanced technique which include intracellular cytokine analysis by flow cytometry combined with multiplex quantization of cytokine levels in recent years, it had provided us a reasonable understanding of the activation profile of cytokine production and new insight in the immune and cellular mechanism in the pathogenesis of SLE, which further clarify the significance of the current body of literatures. This had provided valuable information on the development of novel therapeutic targets for treating SLE. This article will focus on the recent advances of cytokines, chemokines, signaling molecules, and the role of PRRs in immunopathogenesis in SLE.

\section{Imbalance of Th1/Th2 Cytokines in SLE}

Cytokines are a group of small peptides or glycoprotein produced by a wide variety of cells with molecular weights between 8 and $30 \mathrm{kDa}$. They had been shown to play an essential role in modulating the immune response against foreign or self-antigens. These mediators have been classified according to their cellular source and effector functions, with the paradigmatic T helper (Th) 1 and Th2 cytokine families best illustrating this division of function. Th1 cells arise in response to dendritic cells- (DCs-) derived interleukin- (IL-) 12 , produce tumor necrosis factor- (TNF-) $\alpha$, interferon(IFN-) $\gamma$, and are involved in mediating strong inflammatory responses to intracellular pathogens. IL-4-mediated Th2 cell 


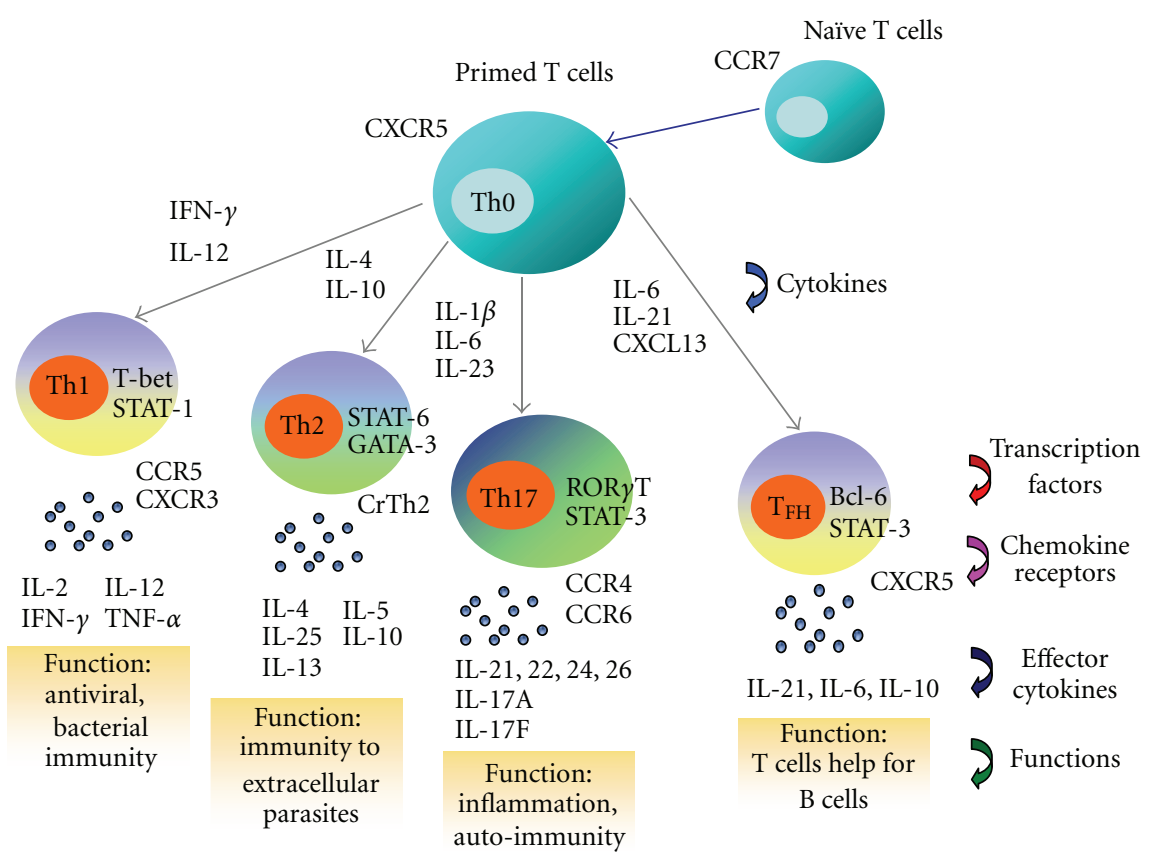

Figure 1: Effector T-cell differentiation (Th1, Th2, Th17 and $\mathrm{T}_{\mathrm{FH}}$ ), the expression of transcription factors, effector cytokines, chemokine receptors, and T-cell functions.

differentiation results in cells that produce cytokines, including IL-4, IL-5, and IL-13, which mediate antibody responses to extracellular pathogens (Figure 1).

The ratios of Th1 and Th2 cytokines have been investigated to determine the cytokine homeostasis in order to determine whether Th1 or Th2 predominance during the development of SLE $[2,3]$. SLE was thought to be a Th2-polarized disease because of the production of auto-antibodies specific for self-antigens [4]. However, significantly elevated cytokines for Th1 response including IL-12, TNF- $\alpha$, and IFN- $\gamma$ were also found in the plasma of SLE patients [5-8]. Th1 dominant immune responses have been generally considered to be pathological in autoimmune disease via the induction of inflammatory reaction. Recently, few cytokines which had been shown to be of great importance in pathogenesis of SLE had surfaced with advent of new technology in detection, which enhances our understanding of their role in SLE-related immune pathway. These cytokines, including IL-12, IL-23, IL-18, IL-21, and IL-33, will be discussed below.

2.1. IL-12. IL-12 is a heterodimeric cytokine of $70 \mathrm{kDa}$ comprising covalently linked p40 and p35 subunit which has been shown to be a central stimulator of Th1-related proinflammatory cytokine that induces IFN- $\gamma$ in both innate and adaptive immunity $[9,10]$. IL-12 had been suggested to be associated with progression of severe glomerulonephritis [11]. Moreover, mRNA levels of p19, p40, and p35 of IL-12 were found to be significantly higher in active SLE patients compared with those patients with inactive disease [12]. Accordingly, serum level of IL-12 was also found to be significantly elevated in SLE patients, and it is associated with the increased level of Th1 cytokine IFN- $\gamma$ but decreased level of Th2 cytokine IL-13 [5, 13, 14]. Conversely, another study reported the decreased ex vivo production of IL12 from peripheral blood polymorphonuclear leukocytes (PMN) stimulated by lipopolysaccharide (LPS) in patients with active SLE [15] using a different ELISA kit. Recently, the elevated plasma IL-12 concentration has been shown to exhibit positive correlation with systemic lupus erythematosus disease activity index (SLEDAI) in SLE patients with renal impairment, supporting IL-12 could play a pathological role in the development of autoinflammatory response in SLE patients with severe disease, probably through the recruitment of the effector leukocytes to the inflamed tissue for orchestrating the immunoresponse at the site of inflammation [16].

2.2. IL-23. IL-23 is a novel heterodimeric cytokine composed of a unique p19 subunit, and a common p40 subunit shared with IL-12. IL-23 shares similar intracellular signal transduction molecules with IL-12, therefore both cytokines exhibit some overlapping function in promoting cellular immunity [17]. Different from IL-12, IL-23 does not promote the development of IFN- $\gamma$-producing Th1 cells, but is crucial for the expansion of a pathogenic $\mathrm{CD} 4^{+} \mathrm{T}$-cell population characterized by the production of IL-17 and IL-22 [18, 19]. Recent studies had shown that the mRNA levels of IL-23p19 were significantly higher in active SLE patients when patients were stratified into different disease activity groups, thereby suggesting that IL-23 should play a role in SLE disease exacerbation [12]. Moreover, the likely significance of IL-23 in autoinflammatory responses was further supported by a more recent report indicated that Th1 transcription factor T-bet could upregulate IL-23 receptor expression and the differentiation of Th1 and Th17 cells in autoimmunity [20] (Figure 1). IL-23 has been reported to enhance the IL-17 
secretion by peripheral blood mononuclear cells (PBMC) from healthy subjects [20]. Moreover, the pathogenic Th17 subgroup expresses elevated level of IL-23 receptor via the activation by T-bet, thereby representing a distinct inflammatory Th cell lineage for the development of organ-specific autoimmune inflammation $[18,20-22]$. In order to better elucidate the involvement of IL-23 in the IL-23/IL-17 autoinflammatory axis and the immunopathological mechanisms of the activation of Th17 cells in SLE, Wong et al. have used IL-23 as an activating agent to demonstrate the direct involvement of IL-23 in the IL-23/IL17 inflammatory axis. It acts to induce a distinct $\mathrm{T}$-cell activation state that produces IL-17 as the effector cytokine that promotes the autoinflammatory responses in SLE [16].

2.3. IL-18. IL-18 was originally identified as a factor that enhances IFN $-\gamma$ production in macrophages, $\mathrm{T}$ lymphocytes, and DCs [23]. Previous studies also reported that the involvement of this Th1-related cytokine in initiating both innate and acquired immune responses [24, 25]. It has been elucidated that IL-18 along with IL-12 is a potent inducer of the inflammatory mediators by $\mathrm{T}$ lymphocytes, causing severe inflammatory disorders in autoimmune diseases such as rheumatoid arthritis (RA) [26]. In SLE, previous studies by our group and others have demonstrated the increased levels of IL-18 in serum/plasma of affected persons, which positively correlated with disease severity [13, 27-29]. Of interest is the elevated urinary IL-18 levels that were found significantly increased in patients with established acute tubular necrosis [30] and the increases within 24 hours after kidney transplantation in patients with delayed allograft dysfunction [31], suggesting that IL-18 may serve as an prognostic marker of renal involvement useful to identify patients at risk of renal failure. Possible pathogenic role of IL18 in lupus has been studied in a mouse model of progressive disease, demonstrating that IL-18 has a multifaceted role in autoimmune lupus, being apparently involved both in the effector phases of the late organ damage and, in some organs, in the initial pathogenic events $[32,33]$.

2.4. IL-21. IL-21 is a pleiotropic cytokine, produced by $\mathrm{CD} 4^{+}$ Th cells, that modulates the differentiation and function of $\mathrm{T}$ cells, B cells, natural killer (NK) cells, and DCs by binding to the receptor composing of the IL-21 receptor- $\alpha$ (IL-21R $\alpha$ ) and the common $\gamma$ chain $[34,35]$. Recent study has intimated that IL-21 can mediate the differentiation and generation of follicular helper $\mathrm{T}$ cells $\left(\mathrm{T}_{\mathrm{FH}}\right)[34,36]$ (Figure 1). Nevertheless, autocrine production of IL-21 from $\mathrm{T}_{\mathrm{FH}}$ cells can potently stimulate the differentiation of $\mathrm{B}$ cells into antibodyforming cells through IL-21R [37]. As a result, dysregulation of $\mathrm{T}_{\mathrm{FH}}$ cell function may relate to the pathogenesis of SLE. IL-21 has been shown to contribute to the development of autoimmune diseases in different animal models of SLE, experimental autoimmune encephalomyelitis, and RA [35]. The genetic association of IL-21 polymorphisms has also been demonstrated in SLE [38]. Recent animal study has revealed that elevated production of IL-21, $\mathrm{T}_{\mathrm{FH}}$ dysfunction within germinal centers, and aberrant positive selection of germinal center B cells are required for the production of autoantibodies and systemic autoimmunity $[39,40]$.

2.5. IL-33. IL-33, a novel member of the IL-1 cytokine family [41], has recently been shown to be involved in the pathogenesis of chronic inflammatory disease [42-44] similar to other family members IL-1 and IL-18 [45]. IL-33 is responsible for the protection against helminth infections and prevention of atherosclerosis by promoting Th2 immune responses [46]. The IL-33 receptor, consisting of ST2 and IL-1 receptor accessory protein, is also widely expressed, particularly on Th2 cells and mast cells [47], to mediate important effector Th2 functions [48]. Although the elevated ST2 protein in the sera of SLE and other patients with autoimmune diseases has been reported [49], its causal relationship with disease activity is still unclear. Recently, significantly elevated serum soluble ST2 (sST2) but not IL-33 has been detected in SLE patients, and the levels of sST2 were found to correlate with the disease activity and severity of these medical conditions. It therefore suggested that the sST2 level may have a potential role as a surrogate marker of disease activity [44]. In this study, no correlation was found between serum IL-33 level and sST2 level, lupus disease activity, or specific organ involvement. In contrast, others reported that serum IL-33 level was significantly increased in SLE compared with healthy controls (HCs). Increased IL33 level was significantly associated with thrombocytopenia, erythrocytopenia, and anti-SSB antibody, suggesting IL-33 may exert biologic effects on erythrocytes and platelets or their precursors in SLE [43]. In summary, the role of the IL33/ST2 system in the pathogenesis of SLE remained unclear.

\section{Imbalance of Th1/Th2 Transcription Factors in SLE}

Although the control of the Th1/Th2 imbalance has been unclear, there is growing evidence to suggest that two major transcription factors, T-box expressed in T cells (T-bet) and GATA binding protein 3 (GATA-3), are the determining factors of T-helper cell differentiation [50]. T-bet, a Th1specific transcription factor, has been postulated to initiate Th1 development while inhibiting Th2 cell differentiation [51]. GATA-3 is a member of the GATA zinc finger protein family, and enhances the development of the Th2 phenotype while inhibiting Th1 cells [52-54]. Recent study had demonstrated that the mRNA levels of T-bet and IFN- $\gamma$ and the relative expression levels of T-bet/GATA-3 and IFN- $\gamma / \mathrm{IL}-4$ were significantly higher, in contrast to the lower expressions of GATA-3 and IL-4, in SLE patients [55]. There were also significant correlations in mRNA expression of T-bet with IFN- $\gamma$ and of GATA- 3 with IL-4. Additionally, the relative expressions of T-bet/GATA-3 and IFN- $\gamma /$ IL- 4 were found to correlate with lupus disease activity. Moreover, the elevated plasma Th1/Th2 cytokine ratio of IL-18/IL-4 was also shown to correlate positively with disease activity in all SLE patients, suggesting the functional activation of peripheral blood Th1 cells in SLE patients. Thus, previous study provided us with new insight that ratio of T-bet/GATA-3 expression is more informative than the level of either transcription 
factor alone, which may be disproportionately affected by the changes in their coexpression in cell populations. The Tbet/GATA-3 expression ratio not only enhances our understanding of Th1/Th2 polarization, it may also serve as a supplementary tool for further assessment of Th1/Th2 status and development of SLE disease activity (Figure 1).

\section{Th17-Mediated Inflammation of SLE}

Apart from Th1 and Th2 cells, there is a novel subset of IL17 producing effector T helper cells, called Th17 cells, whose dysregulation is thought to participate in the pathogenesis of SLE $[56,57]$. Transforming growth factor (TGF)- $\beta$, IL-6, IL21 , and IL-23 have been implicated for Th17 formation [58, 59]. Other proteins involved in their differentiation are signal transducer and activator of transcription 3 (STAT3) and the retinoic-acid-receptor-related orphan receptors alpha $(\operatorname{ROR} \alpha)$ and gamma $(\mathrm{ROR} \gamma)$ [58]. Moreover, effector cytokines associated with this cell type are IL-17, IL-21, and IL-22 [60] (Figure 1). We herein highlighted some of the biological effects of IL-17 implication for Th17-mediated inflammation of SLE.

IL-17 is a type I $17-\mathrm{kDa}$ transmembrane protein that comprises six members and five receptors mostly produced by activated $\mathrm{T}$ cells [61]. It is a pleiotropic proinflammatory cytokine that enhances $\mathrm{T}$-cell priming and stimulates epithelial, endothelial, and fibroblastic cells to produce multiple proinflammatory mediators, including IL-1, IL-6, TNF- $\alpha$, and chemokines [62]. Additionally, IL-17 also exerts its effects through the recruitment of monocytes and neutrophils by increasing the local production of chemokines (IL-8, monocyte chemoattractant protein-1, growth-related oncogene protein- $\alpha$ ), the facilitation of T-cell infiltration and activation by stimulating the expression of intercellular adhesion molecule- 1 by $\mathrm{T}$ cells as well as the amplification of the immune response by inducing the production of IL-6, prostaglandin $\mathrm{E}_{2}$, granulocyte-macrophage colony-stimulating factor, and granulocyte colony-stimulating factor [63]. Lastly, this cytokine synergizes with other cytokines, in particular with IL- $1 \beta$, TNF- $\alpha$, and IFN- $\gamma$ [63].

Wong et al. have demonstrated that SLE patients have higher plasma/serum levels of IL-17 than HCs $[13,16,56]$, which positively associated with SLE disease activity [16]. Accordingly, the frequency of IL-17-producing T cells is increased in peripheral blood of SLE patients [16, 64]. Significant levels of IL-17 and IFN- $\gamma$ were detected in T cells from SLE patients [64]. Additionally, overproduction of total immunoglobulin G (IgG), antidouble stranded DNA, and IL- 6 by PBMC of patients with lupus nephritis was observed upon the stimulation with IL-17 [65], suggesting a potential role of IL-17 in human lupus progression. On the other hand, no elevation of IL-17 was found in serum of cohort of Japanese lupus patients [66]. Most recent evidence suggested that the ability of regulatory $\mathrm{T}$ cells $\left(\mathrm{T}_{\text {regs }}\right)$ to express IFN- $\gamma$ and IL-17 was impaired in SLE patients, whereas the proportion of $\mathrm{T}_{\text {regs }}$ was similar between SLE patients and HCs [67]. Additionally, studies in mice support the concept that IL-17 and Th17 cells may be involved in the development of lupus nephritis $[56,68]$. For instance,
IL-17 was recently found to be critical for the formation of autoreactive germinal centres in autoimmune BXD2 mice, a strain that develops a lupus-like syndrome [69]. In a spontaneous mouse model of lupus, the New Zealand Black (NZB) mice, stimulation of splenocytes with nucleosomes as an autoantigen results in the activation of large numbers of IL-17-secreting T cells [70]. Upon adoptive transfer to naïve recipient mice, IL-23-dependent IL-17 producing $\mathrm{CD}^{+}$effector T-cell subset Th17 can invade the target organ and promote the development of organ-specific autoimmune inflammation. Consistently, Wong et al. also found that the proinflammatory cytokine IL-23 and IL-12 can promote the disease severity by activating pathogenic Th1 and Th17 cells via the induction of downstream Th1 chemokine CXCL10 and inflammatory cytokine IL-17 in SLE, demonstrating that the IL-23/IL-17 axis of inflammation and related molecules may arise as a therapeutic target for treating autoimmune disease.

\section{Chemokines in SLE}

Chemokines in itself refer to a group of smaller cytokines (mass between 8 to $12 \mathrm{kDa}$ ) with chemotactic properties, which are classified into four families according to the location of cysteine residues. The four chemokine groups are $\mathrm{CC}$, $\mathrm{C}, \mathrm{CXC}$, and $\mathrm{CX}_{3} \mathrm{C}$, where $\mathrm{C}$ is a cysteine and $\mathrm{X}$ is any amino acid residue [71]. These small molecules have had welldefined roles in directing cell migration necessary for the initiation of $\mathrm{T}$ cell immune response, attraction of appropriate effector cells to sites of inflammation, and regulation of differential recruitment of T helper (Th1 and Th2) lymphocytes [72-74]. There has been growing evidence suggesting that infiltration of $\mathrm{T}$ lymphocytes and other leucocytes into the sites of inflammation plays a critical role in organ involvement in SLE [75]. Recent studies have also shown that chemokines and their receptors are intimately involved in regulating organ-specific leucocyte trafficking and inflammation, suggesting their important roles in the pathophysiology of autoimmune diseases such as RA, multiple sclerosis, and SLE [76-78]. Chemokine CXCL13 in emerging studies had consolidated the important role of these chemokines in pathogenesis of SLE. Other chemokines that will be briefly discussed in this article mainly include CC and CXC chemokines which had been shown to play some roles in SLE disease.

5.1. CXCL13. CXCL13/B lymphocyte chemoattractant (BLC) is a small cytokine belonging to the CXC chemokine family that is produced by cells in the omentum, peritoneal macrophages, and DCs $[79,80]$, which is selectively chemotactic for B cells including both the B1 and B2 subsets by interacting with specific chemokine receptor CXCR5 $[79,81]$. The accumulation of B1 cells in the peritoneal cavity and spleen are responsible for the body cavity immunity and the production of autoantibody for the development of autoimmune disease in the murine model $[79,82,83]$. Elevated levels of B1 cells have been documented in patients with autoimmune disorders such as Sjogren's syndrome and RA [84, 85]. Previous studies using murine model of SLE 
showed that CXCL13 is highly produced by CD11 $\mathrm{b}^{+} \mathrm{CD} 11 \mathrm{c}^{+}$ DCs in the target organs including thymus and kidney for the chemoattraction of B1 cells into target organ [83, 86-88]. Therefore, the elevated expression of CXCL13 by myeloid dendritic cells (mDCs) in the target organs may play a crucial role in breaking the immune tolerance in the thymus leading to the activation of self-reactive $\mathrm{CD}^{+}{ }^{+} \mathrm{Th}$ cells and the recruitment of autoantibody producing $B$ cells in the development of murine lupus $[83,87,88]$. In addition to that, studies have revealed that CXCL13 can induce the trafficking of distinct $\mathrm{CXCR}^{+} \mathrm{T}$ cells designated as $\mathrm{T}_{\mathrm{FH}}$ which are specifically involved in high-affinity IgG production in germinal centers developed within B-cell follicles of secondary lymphoid tissues including lymph nodes, spleen, and tonsils $[36,89-91] . \mathrm{CD}^{+} \mathrm{T}_{\mathrm{FH}}$ cells, located at B-cell follicles, provide a T helper function to $\mathrm{B}$ cells and represents one of the most numerous and important subsets of effector T cells in lymphoid tissue $[37,92]$. Several studies demonstrated that B-cell chemokine CXCL13 is ectopically and highly expressed in thymus and kidney in murine model for SLE. Studies on humans also demonstrated that serum CXCL13 level was significantly elevated in SLE patients and the elevation correlated significantly with SLE disease activity $[93,94]$. As anti-TNF- $\alpha$ treatment was found to be able to reduce the plasma level of CXCL13 in RA patients [95], it had been postulated that serum level of CXCL 13 can act as a disease activity marker for both RA and SLE patients.

5.2. CC Chemokines. Monocyte chemoattractant protein-1 (MCP-1/CCL2) is a prototype CC chemokine, which can attract monocytes, T cells, NK cells, and basophils [96, 97]. An increase of serum MCP-1/CCL2 was observed with the progression of disease activity in SLE patients compared to HCs [98]. Further investigation reported that cerebral spinal fluids (CSF) MCP-1/CCL2 levels were significantly higher in neuropsychiatric syndromes of systemic lupus erythematosus (NPSLE) patients than those non-NPSLE patients [99]. Regulated upon activation, normal T-cell-expressed and secreted (RANTES)/CCL5 is another CC chemokine which attracts monocytes, memory T cells, and NK cells [100]. Increased plasma RANTES/CCL5 concentrations were found in SLE patients more than in controls, and correlated significantly with SLEDAI score [101]. Moreover, the expression of miR-125a was found to contribute to the elevated expression of RANTES/CCL5 in SLE [102]. In addition to that, studies from animal models and patients with lupus nephritis demonstrated that inflammatory chemokines, especially CCL2 and CCL5, are detectable in kidney tissues and urine before other signs of inflammation [103-106]. With this finding, urine chemokines had been proposed as a possibility to serve as biomarkers for renal SLE flare [107], suggesting that the reduced plasma concentration of these circulating chemokines in lupus patients with renal involvement may result from a protein leakage in the urine.

5.3. CXC Chemokines. Interferon-gamma inducible protein10 (IP-10)/CXCL10 and monokine induced by gamma-interferon (MIG)/CXCL9, the prototype of the CXC family, have chemotactic activity mainly for activated Th1 cells and are involved in the pathogenesis of various Th1-dominant autoimmune diseases $[71,108]$. Their synthesis and expression from neutrophils, macrophages, and other immune cells are induced by IFN- $\gamma$, and this response is suppressed by IL-10 and IL-4 $[71,109]$. Th1 cells and IFN- $\gamma$ had been shown to be important for cell-mediated inflammation in developing autoimmune disease such as SLE [5], thus implicated that these chemokines might have an important role in pathogenesis of SLE. Furthermore, several studies have shown that levels of IP-10/CXCL10 and MIG/CXCL9 were significantly elevated in active SLE $[98,110,111]$. Moreover, Okamoto et al. reported that IP-10/CXCL10 was upregulated in the central nervous system (CNS) fluid of NPSLE [112, 113], suggesting that IP-10/MCP-1 ratio in CSF is a useful diagnostic marker of NPSLE [112]. On the other hand, CXC chemokines CXCL8 and CXCL1 are potent chemoattractants and activators of T cells, neutrophils, thereby enhancing their proinflammatory and proangiogenic activities [114]. They also stimulate neutrophil degranulation to release reactive oxygen radicals, thereby inducing an acute inflammatory reaction $[115,116]$. They had also been shown to be significantly elevated in serum of patient with active lupus, and the elevation was associated with disease activity [111].

\section{Intracellular Signaling Pathways in SLE}

Signal transduction refers to an ordered biochemical process by which a signal or stimulus is transferred within a single cell. This cascade begins with binding of extracellular signaling molecules to cell surface receptors, triggering an initial stimulus that propagated into the cytoplasm. Nowadays, the most well-known and established signal transduction pathway that has been identified is mitogen-activated protein kinase (MAPK) pathway. MAPKs are serine and threonine protein kinases that can be activated by phosphorylation in response to extracellular stimuli, such as mitogens, growth factors, cytokines, and osmotic stress [117, 118]. Nuclear translocation of activated MAPKs can induce and transactivate transcription factors including nuclear factor- (NF-) $\kappa \mathrm{B}$ and activator protein 1 , which facilitate the modulation of gene transcription in cellular activation, proliferation, apoptosis, and the expression of cytokines, chemokines, adhesion molecules, and metalloproteinases [117, 118]. Three main distinct MAPKs, p42/p44 extracellular signal-regulated kinase (ERK), c-Jun NH2-terminal protein kinase (JNK), and p38 MAPK, have been identified in mammalian cells. The activation of NF- $\kappa \mathrm{B}$, JNK, and p38 MAPK plays crucial roles in cytokine-mediated signaling pathways regulating the release of chemokines and the expression of adhesion molecules of eosinophils and Th cells [119-121]. Activation of p38 MAPK has been shown to be crucial for B-cell activation leading to Ig production, and p38 MAPK regulates the production of a number of cytokines, including IL- 6 that promotes the differentiation and survival of plasma cells [122]. Moreover, B-cell-activating factor of the TNF family, an essential factor for B-cell activation and differentiation, was regulated through JNK and p38 MAPK [123]. Furthermore, nuclear factor of activated T cells (NFAT), a downstream 
transcription factor of the ERK and JNK pathways, is essential for $\mathrm{T}$ and $\mathrm{B}$ lymphocyte activation and differentiation [124], and specific anti-NFAT drug therapy has been shown to be pharmacologic armamentarium against RA, inflammatory arthropathies, and related autoimmune disorders [125].

\section{Interaction between Cytokines, Chemokines, and Signaling Molecules in SLE}

As mentioned before, immunopathogenesis of SLE is a complex process that involved the interaction and synergistic effect of various cytokines, chemokines, and signaling molecules which perpetuate the disease activity in SLE. This section below will highlight the recent update on the interaction between all these agents in promoting the disease activity in SLE.

7.1. Role of IL-18 and Chemokines. The potential role of IL18 and chemokines in the exacerbation of SLE disease had been highlighted in a study, which provided valuable information on the development of SLE disease markers [111]. In this study, plasma concentration of CXCL10, CCL5, CXCL9, CXCL8, CXCL1, and CCL2 was significantly elevated in SLE patients and the elevation was correlated significantly with disease activity. Furthermore, plasma concentration of IL18 was found to be correlated positively with production of CXCL10, CXCL9, CXCL1, and CXCL8 in SLE patients, it was also shown to be a potent costimulus for the induction of these chemokine release from activated PBMC as there was a significant increase in ex vivo production of these inflammatory chemokines when their PBMC were cultured in the presence of IL-18.

This enhances our knowledge that successful delivery of the appropriate population of leucocytes to sites of acute inflammation will depend on the repertoire of inducible chemokines synthesized locally, and the temporal expression of chemokine receptors on the leucocytes. Meanwhile, the chemokine expressions are influenced by proinflammatory cytokines, mainly IL-18, to present in the local environment of the cells at the time of stimulation. Furthermore, inflammatory activities of IL-18, together with the induction of Th1 cytokine IFN- $\gamma$ and the activation of Th cells, natural killer cells (NK), and cytotoxic T lymphocytes-inflammatory chemokines, may even enhance the Th1-mediated inflammatory process, the activation of NK and T cells, and the migration of macrophages for initiating and perpetuating the Th1 immune response in SLE. In summary, the correlation of raised plasma concentration and ex vivo production of inflammatory chemokines with disease activity, and their association with IL-18, supports that the chemotaxis of Th1/Th2 lymphocytes and neutrophils is important in SLE pathogenesis.

7.2. Role of CXCL13 and $I L-21$. A recent study [93] had shown that CXCL13 and IL-21 may relate with the immunopathogenesis mediated by the function of $\mathrm{T}_{\mathrm{FH}}$ cells in SLE as serum level of all these cytokines were found to be significantly elevated in lupus patient with the increase in CXCL13 concentration correlated positively and significantly with SLEDAI score. Furthermore, cell surface expression of CXCR5 on Th and B cells and IL-21R on B cells was found to be significantly lower in SLE patients, which indicated that most differentiated $\mathrm{T}_{\mathrm{FH}}$ cells migrate out from circulation into lymphoid organ upon activation during the disease development of SLE. This piece of information suggests that the elevated production of CXCL13, BAFF, and IL-21 may be associated with the function of $\mathrm{T}_{\mathrm{FH}}$ for the immunopathogenesis in SLE, and CXCL13 may serve as a potential disease marker of SLE.

7.3. Role of $I L-23, I L-17, I L-18$, Th17, and CXCL10. The pathogenic role of IL-23/IL-17 autoinflammatory axis in SLE had been elucidated in a recent study [16]. First, parallelly elevated plasma IL-12, IL-17, and CXCL10 concentrations exhibited positive correlation with the SLEDAI in their lupus patients with renal impairment, which supported that these cytokines cascade could play a pathological role in the development of autoinflammatory response in SLE patients with severe disease, through the recruitment of the effector leukocytes into the inflamed tissue for orchestrating the immunoresponse at the site of inflammation. Second, when using IL-23 as activator, the CD3 and CD28 costimulated PBMC responded with an aberrant ex vivo production of IL-17, which provided robust evidence on the direct involvement of IL-23 in the IL-23/IL-17 inflammatory axis, which acts to induce a distinct T-cell activation state that produces IL-17 as the effector cytokine that promotes the autoinflammatory responses in SLE. Third, ex vivo production of IL-12, IL-23, and IL-17 from PMBC was significantly enhanced by the presence of IL-18 which indicated that the expressions of inflammatory cytokines IL-12, IL-23, and IL-17 and activation of Th17 cells are in part influenced by proinflammatory cytokine IL-18 present in the local environment of the cells during stimulation. IL-23-mediated activation of IL-17-producing Th cells in SLE patients may closely be influenced by IL-18 activation, which orchestrates the inflammation of SLE. In conclusion, proinflammatory cytokine IL-18 and IL12 family cytokines IL-12 and IL-23 can promote the disease severity by activating pathogenic Th1 and Th17 cells via the induction of downstream Th1 chemokine CXCL10 and inflammatory cytokine IL-17 in SLE.

7.4. Role of MAPK, IL-18, and CXCL10. As for the roles of MAPK transduction pathway in pathogenesis of SLE, highly abnormal ERK and NF- $\kappa \mathrm{B}$ activities in $\mathrm{T}$ lymphocytes of lupus patients had been reported $[126,127]$. The lyn kinase deficiency in B lymphocytes and decreased ras-MAPK in T lymphocytes had also been demonstrated in SLE patients [128-130]. A recent study had further consolidated the facts that p38 MAPK and JNK are the key signaling molecules in regulating the inflammation-mediated hyperactivity of $\mathrm{T}$ and B lymphocytes in SLE [131]. In this study, the basal expressions of $\mathrm{p} 38 \mathrm{MAPK}$ in $\mathrm{CD}^{+} \mathrm{T}$ lymphocytes, $\mathrm{CD}^{+} \mathrm{T}$ lymphocytes, and B lymphocytes had been shown to be significantly higher in SLE patients, and the expression of phospho-p38 MAPK in CD4 ${ }^{+} \mathrm{T}$ lymphocytes, $\mathrm{CD}^{+} \mathrm{T}$ lymphocytes, and $\mathrm{B}$ lymphocytes, and phospho-JNK in $\mathrm{CD} 8^{+} \mathrm{T}$ 
lymphocytes and B lymphocytes was also significantly elevated in SLE patients upon the activation by IL-18, exhibiting significant correlation with the plasma concentrations of Th1 chemokine CXCL10. Furthermore, the expression of phospho-JNK in IL-18-activated $\mathrm{CD}^{+} \mathrm{T}$ lymphocytes and the relative percentage (\%) fold increase of the expression of phospho-JNK upon IL-18 activation in B lymphocytes were significantly correlated with SLE disease activity index. Therefore, the inflammation-mediated activation of JNK and p38 MAPK signaling pathways in T and B lymphocytes can be the underlying intracellular mechanism causing lymphocyte hyperactivity in SLE.

\section{Pattern-Recognition Receptors in SLE: Friend or Foe}

An infectious etiology of SLE has been a longstanding hypothesis [132-134] and with the discovery of PRRs in SLE, the role of bacteria and viruses in the pathogenesis of SLE has been invigorated. PRRs can alert and activate the innate immune system through recognizing the conserved molecular patterns to distinguish extrinsic pathogen-associated molecular patterns (PAMPs) and endogenous danger-associated molecular patterns (DAMPs). Several PRRs participated in the recognition of viral components, such as genomic DNA and RNA, in a replication-independent way. Additionally, cells express intracellular RNA helicases that function as PRRs of actively replicating viruses [135]. These PRRs are also essential in establishing antiviral immunity by triggering type I interferon responses.

8.1. Toll-Like Receptor in SLE. Being the most studied PRRs, Toll-like receptors- (TLRs-) mediated intracellular signaling is a crucial link between innate and adaptive immunity [136], which principally sense structurally conserved molecular motifs called PAMPs for triggering NF- $\kappa \mathrm{B}$, p38 MAPK, JNK, and the IFN pathways, which results in the translocation of transcription factors, cytokine modulation, and IFN-stimulated gene regulation leading to inflammatory responses [137]. The stimulation of TLR by PAMPs is an important prerequisite for the induction of various autoimmune diseases [138]. To date, at least 10 human TLRs have been identified, and the functions of human TLR1-9 have been characterized $[138,139]$. Cell surface TLRs (TLR-1, 2, 4,5 , and 6) are designed for the engagement of extracellular pathogens, whereas the intracellular TLRs (TLR-3, 7, 8, and 9) are against intracellular pathogen-derived products [140].

Animal studies of SLE have indicated that TLRs are important in the pathogenesis of lupus mouse. For instance, in myeloid differentiation primary response gene $(\mathrm{MyD}) 8^{8-}$ deficient MRL/MpJ-Fas(lpr) (MRL/lpr) mice, both MyD88dependent and -independent innate signals were found to play a crucial role in the development of autoimmune nephritis [141]. Treatment of lupus-prone mice with a dual inhibitor of TLR-7 and TLR-9 was found to lead to the reduction of autoantibody production and amelioration of disease symptoms [142]. Lupus-prone mice deficient in TLR-7 also failed to generate antibodies against RNA-containing antigens such as Smith, which decreased lymphocyte activation and serum IgG [143]. Conversely, the absence of TLR-9 can exacerbate the disease activity by the activation of lymphocytes and plasmacytoid dendritic cells (pDCs), inducing the subsequent increase of serum IgG and IFN- $\gamma$ [143]. Emerging evidence revealed that TLR-9 was involved in classswitching to pathogenic autoantibody production in SLE $[144,145]$. Accordingly, patients with active SLE had been shown to have upregulated expression of TLR-9 in peripheral blood memory and plasma B lymphocytes, suggesting that endogenous nucleic acids released during apoptosis may stimulate B lymphocytes via TLR-9 and contribute to SLE pathogenesis [146]. Upregulated expression of TLR-7 and TLR-9 mRNA, together with IFN- $\gamma$ mRNA in PBMC, may also contribute to the pathogenesis of human lupus [147]. Consistently, other study also revealed that PBMCs of SLE patients with a higher expression of TLRs are more prone to be activated by diverse TLR ligands when compared to HCs $[147,148]$, suggesting that the innate immune response for extracellular pathogens and self-originated DNA plays immunopathological roles via TLR activation in SLE.

Recent study by our group found that antagonist-mediated diminished intracellular TLRs might act as potent activators of innate immune responses involved in the higher prevalence of human papillomavirus infection (HPV) in SLE [149]. TLR antagonist, such as hydroxychloroquine, might decrease the expression of intracellular TLRs in SLE patients, thereby increasing the risk of acquiring HPV infection. Moreover, high-risk HPV infections may play a predominant role in further downregulating the expression of intracellular TLR in SLE patients with HPV infection resulting in a higher prevalence of persistent infection, suggesting that the avoidance of stimulation and downregulation of the innate immune system, which might permit persistence of HPV in SLE, is evidently part of an immune evasion strategy used by oncogenic HPV establishing of persistence infection [149].

8.2. Nucleotide-Binding Oligomerization Domain Containing 2 in SLE. In contrast to the well-elucidated membranebound TLRs, cytoplasmic nucleotide binding oligomerisation domain (NOD) receptors are a new family of PRRs for the recognition of extracellular PAMPs $[150,151]$. Two NOD-like receptor (NLR) proteins, namely, NOD1 and NOD2, can participate in the signaling events triggered by host recognition of specific motifs of bacterial peptidoglycans (PGNs) and, upon activation, induce the production of proinflammatory mediators [150]. NOD1 recognizes products from gram-negative bacteria (diaminopimelic acids), whereas NOD2 senses muramyl dipeptide (MDP), a peptidoglycan derived peptide from gram-negative as well as gram-positive bacteria [152]. It has been shown that NLRs complement and synergize with TLRs in innate immune responses [153-156]. NLRs are associated with Crohn's disease and inflammatory arthritis [155-157]. However, the precise mechanisms by which NOD-mediated recognition of PGNs in the pathogenesis of inflammatory diseases are still unclear. Apart from the putative link between the genetic variants of NOD2 and SLE [158-163], little is known about the expression and function of NOD2 in SLE [164]. Our recent study demonstrated an overexpression of NOD2 in 
monocyte of immunosuppressant naïve SLE patients with longer process might lead to activation of PBMCs to produce proinflammatory cytokines, implicating the innate immune response for extracellular pathogens in immunopathological mechanisms in SLE [165]. Conversely, immunosuppressive therapy may downregulate the expression of NOD2 in $\mathrm{CD} 8^{+}$ T, monocytes, mDCs, and pDCs in SLE which subsequently reduce regulatory cytokine IL-10, allowing for an aberrant inflammatory response contributing towards the regulation of immunopathological mechanisms of SLE, at the expense of increasing risk of bacterial infection [165]. NOD1 expression in PBMC subsets of SLE patients and HCs could not be detected using flow cytometry [165].

Recently, increased prevalence of HPV and tuberculosis (TB) in SLE has been reported by our group and others [166169]. Whether the immune evasion strategy, specific bacteria, or virus could escape PRRs recognition, establishment of persistent infection in SLE playing a significant part in hostpathogenic interaction need further considerations. Further elucidation of the infectious process and immune response against infections and exploration of the efficacy of agonists as therapeutic tools for eliminating infected cells in SLE will be worth investigation.

\section{Conclusion}

The understanding of the immunopathologic mechanisms of SLE has been gradually evolving with budding studies on assessing the activation of monocytes, $\mathrm{T}$, and $\mathrm{B}$ lymphocytes upon stimulation of various stimuli and also underlying intracellular signaling mechanisms. This further enhanced our current and limited knowledge regarding the cellular mechanism and pathway in the immunopathogenesis of SLE, which had shed light on developing potential and novel therapies in treating this chronic immunological disorder. Therapeutic inhibitors of the pathways of JNK or p38MAPK [170, 171] and antibodies against IL-21, CXCL13 [172, 173], and TLR [174, 175] have been shown to exhibit some promising beneficial effects. Hopefully, with the advent of more advanced technology and emergence of more studies, our understanding for this elusive disease can be further strengthened in the future.

\section{Acknowledgments}

Work in the authors' laboratories is funded by the Chinese University of Hong Kong Direct Grant, Research Grants Council, and Health and Health Services Research Fund.

\section{References}

[1] L. D. Heinlen, M. T. McClain, J. Merrill et al., "Clinical criteria for systemic lupus erythematosus precede diagnosis, and associated autoantibodies are present before clinical symptoms," Arthritis and Rheumatism, vol. 56, no. 7, pp. 2344-2351, 2007.

[2] J. F. Viallard, J. L. Pellegrin, V. Ranchin et al., "Th1 (IL-2, interferon-gamma (IFN- $\gamma$ )) and Th2 (IL-10, IL-4) cytokine production by peripheral blood mononuclear cells (PBMC) from patients with systemic lupus erythematosus (SLE), Clinical and Experimental Immunology, vol. 115, no. 1, pp. 189-195, 1999.

[3] K. Miyake, M. Akahoshi, and H. Nakashima, "Th subset balance in lupus nephritis," Journal of Biomedicine and Biotechnology, vol. 2011, Article ID 980286, 2011.

[4] C. Mohan, S. Adams, V. Stanik, and S. K. Datta, "Nucleosome: a major immunogen for pathogenic autoantibody-inducing T cells of lupus," Journal of Experimental Medicine, vol. 177, no. 5, pp. 1367-1381, 1993.

[5] Y. Tokano, S. Morimoto, H. Kaneko et al., "Levels of IL-12 in the sera of patients with systemic lupus erythematosus (SLE)-relation to Th1- and Th2-derived cytokines," Clinical and Experimental Immunology, vol. 116, no. 1, pp. 169-173, 1999.

[6] E. M. Davas, A. Tsirogianni, I. Kappou, D. Karamitsos, I. Economidou, and P. C. Dantis, "Serum IL-6, TNF $\alpha$, p55 $\operatorname{srTNF} \alpha$, p7 5 srTNF $\alpha$, srIL- $2 \alpha$ levels and disease activity in systemic lupus erythematosus," Clinical Rheumatology, vol. 18, no. 1, pp. 17-22, 1999.

[7] M. Al-Janadi, S. Al-Balla, A. Al-Dalaan, and S. Raziuddin, "Cytokine profile in systemic lupus erythematosus, rheumatoid arthritis, and other rheumatic diseases," Journal of Clinical Immunology, vol. 13, no. 1, pp. 58-67, 1993.

[8] S. A. Apostolidis, L. A. Lieberman, K. Kis-Toth, J. C. Crispin, and G. C. Tsokos, "The dysregulation of cytokine networks in systemic lupus erythematosus," Journal of Interferon and Cytokine Research, vol. 31, no. 10, pp. 769-779, 2011.

[9] C. L. Langrish, B. S. McKenzie, N. J. Wilson, R. De Waal Malefyt, R. A. Kastelein, and D. J. Cua, "IL-12 and IL-23: master regulators of innate and adaptive immunity," Immunological Reviews, vol. 202, pp. 96-105, 2004.

[10] G. Trinchieri, "Interleukin-12 and the regulation of innate resistance and adaptive immunity," Nature Reviews Immunology, vol. 3, no. 2, pp. 133-146, 2003.

[11] A. R. Kitching, A. L. Turner, G. R. A. Wilson et al., "IL-12p40 and IL-18 in crescentic glomerulonephritis: IL-12p40 is the key Th1-defining cytokine chain, whereas IL-18 promotes local inflammation and leukocyte recruitment," Journal of the American Society of Nephrology, vol. 16, no. 7, pp. 2023-2033, 2005.

[12] X. Huang, J. Hua, N. Shen, and S. Chen, "Dysregulated expression of interleukin-23 and interleukin-12 subunits in systemic lupus erythematosus patients," Modern Rheumatology, vol. 17, no. 3, pp. 220-223, 2007.

[13] C. K. Wong, C. Y. Ho, E. K. Li, and C. W. K. Lam, "Elevation of proinflammatory cytokine (IL-18, IL-17, IL-12) and Th2 cytokine (IL-4) concentrations in patients with systemic lupus erythematosus," Lupus, vol. 9, no. 8, pp. 589-593, 2000.

[14] S. Aggarwal, N. Ghilardi, M. H. Xie, F. J. De Sauvage, and A. L. Gurney, "Interleukin-23 promotes a distinct CD4 T cell activation state characterized by the production of interleukin-17," Journal of Biological Chemistry, vol. 278, no. 3, pp. 1910-1914, 2003.

[15] C. Y. Tsai, T. H. Wu, C. L. Yu, Y. Y. Tsai, and C. T. Chou, "Decreased IL-12 production by polymorphonuclear leukocytes in patients with active systemic lupus erythematosus," Immunological Investigations, vol. 31, no. 3-4, pp. 177-189, 2002.

[16] C. K. Wong, L. C. W. Lit, L. S. Tam, E. K. M. Li, P. T. Y. Wong, and C. W. K. Lam, "Hyperproduction of IL-23 and IL-17 in patients with systemic lupus erythematosus: implications for Th17-mediated inflammation in auto-immunity," Clinical Immunology, vol. 127, no. 3, pp. 385-393, 2008. 
[17] C. S. R. Lankford and D. M. Frucht, "A unique role for IL-23 in promoting cellular immunity," Journal of Leukocyte Biology, vol. 73, no. 1, pp. 49-56, 2003.

[18] Z. Chen, C. M. Tato, L. Muul, A. Laurence, and J. J. O’Shea, "Distinct regulation of interleukin-17 in human $\mathrm{T}$ helper lymphocytes," Arthritis and Rheumatism, vol. 56, no. 9, pp. 2936-2946, 2007.

[19] M. A. Hoeve, N. D. L. Savage, T. de Boer et al., "Divergent effects of IL-12 and IL-23 on the production of IL-17 by human T cells," European Journal of Immunology, vol. 36, no. 3, pp. 661-670, 2006.

[20] A. R. Gocke, P. D. Cravens, L. H. Ben et al., "T-bet regulates the fate of Th1 and Th17 lymphocytes in autoimmunity," Journal of Immunology, vol. 178, no. 3, pp. 1341-1348, 2007.

[21] J. Furuzawa-Carballeda, M. I. Vargas-Rojas, and A. R. Cabral, "Autoimmune inflammation from the Th17 perspective," Autoimmunity Reviews, vol. 6, no. 3, pp. 169-175, 2007.

[22] E. Bettelli, M. Oukka, and V. K. Kuchroo, " $\mathrm{T}_{H}-17$ cells in the circle of immunity and autoimmunity," Nature Immunology, vol. 8, no. 4, pp. 345-350, 2007.

[23] C. A. Dinarello, "IL-18: a $\mathrm{T}_{H} 1$-inducing, proinflammatory cytokine and new member of the IL-1 family," Journal of Allergy and Clinical Immunology, vol. 103, no. 1, pp. 11-24, 1999.

[24] T. Hoshino, R. H. Wiltrout, and H. A. Young, "IL-18 is a potent coinducer of IL-13 in NK and T cells: a new potential role for IL-18 in modulating the immune response," Journal of Immunology, vol. 162, no. 9, pp. 5070-5077, 1999.

[25] T. Yoshimoto, H. Mizutani, H. Tsutsui et al., "IL-I 8 induction of IgE: dependence on CD4 ${ }^{+}$T cells, IL-4 and STAT6," Nature Immunology, vol. 1, no. 2, pp. 132-137, 2000.

[26] T. A. Fehniger, M. H. Shah, M. J. Turner et al., "Differential cytokine and chemokine gene expression by human NK cells following activation with IL-18 or IL-15 in combination with IL-12: implications for the innate immune response," Journal of Immunology, vol. 162, no. 8, pp. 4511-4520, 1999.

[27] C. K. Wong, E. K. Li, C. Y. Ho, and C. W. K. Lam, "Elevation of plasma interleukin-18 concentration is correlated with disease activity in systemic lupus erythematosus," Rheumatology, vol. 39, no. 10, pp. 1078-1081, 2000.

[28] P. Amerio, A. Frezzolini, D. Abeni et al., "Increased IL-18 in patients with systemic lupus erythematosus: relations with Th-1, Th-2, pro-inflammatory cytokines and disease activity. IL-18 is a marker of disease activity but does not correlate with pro-inflammatory cytokines," Clinical and Experimental Rheumatology, vol. 20, no. 4, pp. 535-538, 2002.

[29] K. Shibatomi, H. Ida, S. Yamasaki et al., "A novel role for interleukin-18 in human natural killer cell death: high serum levels and low natural killer cell numbers in patients with systemic autoimmune diseases," Arthritis and Rheumatism, vol. 44, no. 4, pp. 884-892, 2001.

[30] C. R. Parikh, A. Jani, V. Y. Melnikov, S. Faubel, and C. L. Edelstein, "Urinary interleukin-18 is a marker of human acute tubular necrosis," American Journal of Kidney Diseases, vol. 43, no. 3, pp. 405-414, 2004.

[31] C. R. Parikh, A. Jani, J. Mishra et al., "Urine NGAL and IL18 are predictive biomarkers for delayed graft function following kidney transplantation," American Journal of Transplantation, vol. 6, no. 7, pp. 1639-1645, 2006.

[32] F. Favilli, C. Anzilotti, L. Martinelli et al., "IL-18 activity in systemic lupus erythematosus," Annals of the New York Academy of Sciences, vol. 1173, pp. 301-309, 2009.

[33] D. Neumann, E. Del Giudice, A. Ciaramella, D. Boraschi, and P. Bossù, "Lymphocytes from autoimmune MRL lpr/lpr mice are hyperresponsive to IL-18 and overexpress the IL-18 receptor accessory chain," Journal of Immunology, vol. 166, no. 6, pp. 3757-3762, 2001.

[34] R. I. Nurieva, Y. Chung, D. Hwang et al., "Generation of $\mathrm{T}$ follicular helper cells is mediated by interleukin-21 but independent of T Helper 1, 2, or 17 cell lineages," Immunity, vol. 29, no. 1, pp. 138-149, 2008.

[35] R. Spolski and W. J. Leonard, "Interleukin-21: basic biology and implications for cancer and autoimmunity," Annual Review of Immunology, vol. 26, pp. 57-79, 2008.

[36] A. Vogelzang, H. M. McGuire, D. Yu, J. Sprent, C. R. Mackay, and C. King, "A fundamental role for interleukin-21 in the generation of T follicular helper cells," Immunity, vol. 29, no. 1, pp. 127-137, 2008.

[37] C. King, S. G. Tangye, and C. R. Mackay, "T follicular helper $\left(\mathrm{T}_{\mathrm{FH}}\right)$ cells in normal and dysregulated immune responses," Annual Review of Immunology, vol. 26, pp. 741-766, 2008.

[38] A. H. Sawalha, K. M. Kaufman, J. A. Kelly et al., "Genetic association of interleukin-21 polymorphisms with systemic lupus erythematosus," Annals of the Rheumatic Diseases, vol. 67, no. 4, pp. 458-461, 2008.

[39] J. A. Bubier, T. J. Sproule, O. Foreman et al., "A critical role for IL-21 receptor signaling in the pathogenesis of systemic lupus erythematosus in BXSB-Yaa mice," Proceedings of the National Academy of Sciences of the United States of America, vol. 106, no. 5, pp. 1518-1523, 2009.

[40] M. A. Linterman, R. J. Rigby, R. K. Wong et al., "Follicular helper T cells are required for systemic autoimmunity," Journal of Experimental Medicine, vol. 206, no. 3, pp. 561-576, 2009.

[41] C. A. Dinarello, "Interleukin-1," Cytokine and Growth Factor Reviews, vol. 8, no. 4, pp. 253-265, 1997.

[42] D. Xu, H. R. Jiang, P. Kewin et al., "IL-33 exacerbates antigeninduced arthritis by activating mast cells," Proceedings of the National Academy of Sciences of the United States of America, vol. 105, no. 31, pp. 10913-10918, 2008.

[43] Z. Yang, Y. Liang, W. Xi, C. Li, and R. Zhong, "Association of increased serum IL-33 levels with clinical and laboratory characteristics of systemic lupus erythematosus in Chinese population," Clinical and Experimental Medicine, vol. 11, no. 2, pp. 75-80, 2011.

[44] M. Y. Mok, F. P. Huang, W. K. Ip et al., "Serum levels of IL-33 and soluble ST2 and their association with disease activity in systemic lupus erythematosus," Rheumatology, vol. 49, no. 3, Article ID kep402, pp. 520-527, 2009.

[45] H. E. Barksby, S. R. Lea, P. M. Preshaw, and J. J. Taylor, "The expanding family of interleukin-1 cytokines and their role in destructive inflammatory disorders," Clinical and Experimental Immunology, vol. 149, no. 2, pp. 217-225, 2007.

[46] F. Y. Liew, N. I. Pitman, and I. B. McInnes, "Disease-associated functions of IL-33: the new kid in the IL-1 family," Nature Reviews Immunology, vol. 10, no. 2, pp. 103-110, 2010.

[47] J. Schmitz, A. Owyang, E. Oldham et al., "IL-33, an interleukin-1-like cytokine that signals via the IL-1 receptorrelated protein ST2 and induces T helper type 2-associated cytokines," Immunity, vol. 23, no. 5, pp. 479-490, 2005.

[48] M. Löhning, A. Stroehmann, A. J. Coyle et al., "T1/ST2 is preferentially expressed on murine Th2 cells, independent of interleukin 4, interleukin 5, and interleukin 10, and important for Th2 effector function," Proceedings of the National Academy of Sciences of the United States of America, vol. 95, no. 12, pp. 6930-6935, 1998.

[49] K. Kuroiwa, T. Arai, H. Okazaki, S. Minota, and S. I. Tominaga, "Identification of human ST2 protein in the sera 
of patients with autoimmune diseases," Biochemical and Biophysical Research Communications, vol. 284, no. 5, pp. 11041108, 2001.

[50] R. W. Y. Chan, F. M. M. Lai, E. K. M. Li et al., "Imbalance of Th1/Th2 transcription factors in patients with lupus nephritis," Rheumatology, vol. 45, no. 8, pp. 951-957, 2006.

[51] S. J. Szabo, S. T. Kim, G. L. Costa, X. Zhang, C. G. Fathman, and L. H. Glimcher, "A novel transcription factor, T-bet, directs Th1 lineage commitment," Cell, vol. 100, no. 6, pp. 655669, 2000.

[52] D. H. Zhang, L. Yang, and A. Ray, "Cutting edge: differential responsiveness of the IL- 5 and IL- 4 genes to transcription factor GATA-3," Journal of Immunology, vol. 161, no. 8, pp. 3817-3821, 1998.

[53] W. Ouyang, M. Löhning, Z. Gao et al., "Stat6-independent GATA-3 autoactivation directs IL-4-independent Th2 development and commitment," Immunity, vol. 12, no. 1, pp. 27$37,2000$.

[54] G. R. Lee, P. E. Fields, and R. A. Flavell, "Regulation of IL-4 gene expression by distal regulatory elements and GATA-3 at the chromatin level," Immunity, vol. 14, no. 4, pp. 447-459, 2001.

[55] L. C. W. Lit, C. K. Wong, E. K. M. Li, L. S. Tam, C. W. K. Lam, and Y. M. D. Lo, "Elevated gene expression of Th1/Th2 associated transcription factors is correlated with disease activity in patients with systemic lupus erythematosus," Journal of Rheumatology, vol. 34, no. 1, pp. 89-96, 2007.

[56] L. A. Garrett-Sinha, S. John, and S. L. Gaffen, "IL-17 and the Th17 lineage in systemic lupus erythematosus," Current Opinion in Rheumatology, vol. 20, no. 5, pp. 519-525, 2008.

[57] E. Lubberts, "IL-17/Th17 targeting: on the road to prevent chronic destructive arthritis?" Cytokine, vol. 41, no. 2, pp. 8491, 2008.

[58] C. Dong, " $\mathrm{T}_{H} 17$ cells in development: an updated view of their molecular identity and genetic programming," Nature Reviews Immunology, vol. 8, no. 5, pp. 337-348, 2008.

[59] N. Manel, D. Unutmaz, and D. R. Littman, "The differentiation of human $\mathrm{T}_{H} 17$ cells requires transforming growth factor- $\beta$ and induction of the nuclear receptor ROR $\gamma \mathrm{t}$," $\mathrm{Na}$ ture Immunology, vol. 9, no. 6, pp. 641-649, 2008.

[60] W. Ouyang, J. K. Kolls, and Y. Zheng, "The biological functions of T Helper 17 cell effector cytokines in inflammation," Immunity, vol. 28, no. 4, pp. 454-467, 2008.

[61] E. Rouvier, M. F. Luciani, M. G. Mattei, F. Denizot, and P. Golstein, "CTLA-8, cloned from an activated T cell, bearing AU-rich messenger RNA instability sequences, and homologous to a herpesvirus Saimiri gene," Journal of Immunology, vol. 150, no. 12, pp. 5445-5456, 1993.

[62] J. K. Kolls and A. Lindén, "Interleukin-17 family members and inflammation," Immunity, vol. 21, no. 4, pp. 467-476, 2004.

[63] A. Nalbandian, J. C. Crispín, and G. C. Tsokos, "Interleukin17 and systemic lupus erythematosus: current concepts," Clinical and Experimental Immunology, vol. 157, no. 2, pp. 209-215, 2009.

[64] J. C. Crispín, M. Oukka, G. Bayliss et al., "Expanded double negative T cells in patients with systemic lupus erythematosus produce IL-17 and infiltrate the kidneys," Journal of Immunology, vol. 181, no. 12, pp. 8761-8766, 2008.

[65] G. Dong, R. Ye, W. Shi et al., "IL-17 induces autoantibody overproduction and peripheral blood mononuclear cell overexpression of IL-6 in lupus nephritis patients," Chinese Medical Journal, vol. 116, no. 4, pp. 543-548, 2003.

[66] K. Kurasawa, K. Hirose, H. Sano et al., "Increased interleukin-17 production in patients with systemic sclerosis,"
Arthritis and Rheumatism, vol. 43, no. 11, pp. 2455-2463, 2000.

[67] S. Dolff, M. Bijl, M. G. Huitema, P. C. Limburg, C. G.M. Kallenberg, and W. H. Abdulahad, "Disturbed Th1, Th2, Th17 and $\mathrm{T}_{\text {reg }}$ balance in patients with systemic lupus erythematosus," Clinical Immunology, vol. 141, no. 2, pp. 197207, 2011.

[68] A. B. Pernis, "Th17 cells in rheumatoid arthritis and systemic lupus erythematosus," Journal of Internal Medicine, vol. 265, no. 6, pp. 644-652, 2009.

[69] H. C. Hsu, P. A. Yang, J. Wang et al., "Interleukin 17-producing $\mathrm{T}$ helper cells and interleukin 17 orchestrate autoreactive germinal center development in autoimmune BXD2 mice," Nature Immunology, vol. 9, no. 2, pp. 166-175, 2008.

[70] H. K. Kang, M. Liu, and S. K. Datta, "Low-dose peptide tolerance therapy of lupus generates plasmacytoid dendritic cells that cause expansion of autoantigen-specific regulatory T cells and contraction of inflammatory Th17 cells," Journal of Immunology, vol. 178, no. 12, pp. 7849-7858, 2007.

[71] A. Zlotnik and O. Yoshie, "Chemokines: a new classification system and their role in immunity," Immunity, vol. 12, no. 2, pp. 121-127, 2000.

[72] F. Sallusto and A. Lanzavecchia, "Understanding dendritic cell and T-lymphocyte traffic through the analysis of chemokine receptor expression," Immunological Reviews, vol. 177, pp. 134-140, 2000.

[73] B. A. Premack and T. J. Schall, "Chemokine receptors: gateways to inflammation and infection," Nature Medicine, vol. 2, no. 11, pp. 1174-1178, 1996.

[74] F. Sallusto, "The role of chemokines and chemokine receptors in T cell priming and Th1/Th2-mediated responses," Haematologica, vol. 84, pp. 28-31, 1999.

[75] R. W. Hoffman, "T cells in the pathogenesis of systemic lupus erythematosus," Frontiers in Bioscience, vol. 6, pp. D1369D1378, 2001.

[76] K. J. Katschke Jr., J. B. Rottman, J. H. Ruth et al., "Differential expression of chemokine receptors on peripheral blood, synovial fluid, and synovial tissue monocytes/macrophages in rheumatoid arthritis," Arthritis and Rheumatism, vol. 44, no. 5, pp. 1022-1032, 2001.

[77] C. L. Galligan, W. Matsuyama, A. Matsukawa et al., "Upregulated expression and activation of the orphan chemokine receptor, CCRL2, in rheumatoid arthritis," Arthritis and Rheumatism, vol. 50, no. 6, pp. 1806-1814, 2004.

[78] H. Bartosik-Psujek, E. Belniak, K. Mitosek-Szewczyk, B. Dobosz, and Z. Stelmasiak, "Interleukin-8 and RANTES levels in patients with relapsing-remitting multiple sclerosis (RR-MS) treated with cladribine," Acta Neurologica Scandinavica, vol. 109, no. 6, pp. 390-392, 2004.

[79] K. M. Ansel, R. B. S. Harris, and J. G. Cyster, "CXCL13 is required for $\mathrm{B} 1$ cell homing, natural antibody production, and body cavity immunity," Immunity, vol. 16, no. 1, pp. 67$76,2002$.

[80] J. L. M. Vissers, F. C. Hartgers, E. Lindhout, C. G. Figdor, and G. J. Adema, "BLC (CXCL13) is expressed by different dendritic cell subsets in vitro and in vivo," European Journal of Immunology, vol. 31, no. 5, pp. 1544-1549, 2001.

[81] D. F. Legler, M. Loetscher, R. S. Roos, I. Clark-Lewis, M. Baggiolini, and B. Moser, "B cell-attracting chemokine 1, a human CXC chemokine expressed in lymphoid tissues, selectively attracts B lymphocytes via BLR1/CXCR5," Journal of Experimental Medicine, vol. 187, no. 4, pp. 655-660, 1998.

[82] K. Hayakawa and R. R. Hardy, "Development and function of B-1 cells," Current Opinion in Immunology, vol. 12, no. 3, pp. 346-354, 2000. 
[83] T. Sato, S. Ishikawa, K. Akadegawa et al., "Aberrant B1 cell migration into the thymus results in activation of CD4 T cells through its potent antigen-presenting activity in the development of murine lupus," European Journal of Immunology, vol. 34, no. 12, pp. 3346-3358, 2004.

[84] M. Dauphinee, Z. Tovar, and N. Talal, "B cells expressing CD5 are increased in Sjogren's syndrome," Arthritis and Rheumatism, vol. 31, no. 5, pp. 642-647, 1988.

[85] C. Plater-Zyberk, R. N. Maini, K. Lam, T. D. Kennedy, and G. Janossy, "A rheumatoid arthritis B cell subset expresses a phenotype similar to that in chronic lymphocytic leukemia," Arthritis and Rheumatism, vol. 28, no. 9, pp. 971-976, 1985.

[86] T. Ito, S. Ishikawa, T. Sato et al., "Defective B1 cell homing to the peritoneal cavity and preferential recruitment of B1 cells in the target organs in a murine model for systemic lupus erythematosus," Journal of Immunology, vol. 172, no. 6, pp. 3628-3634, 2004.

[87] S. Ishikawa, T. Sato, M. Abe et al., "Aberrant high expression of B lymphocyte chemokine (BLC/CXCL13) by

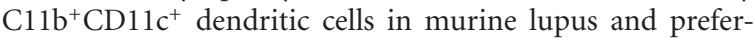
ential chemotaxis of B1 cells towards BLC," Journal of Experimental Medicine, vol. 193, no. 12, pp. 1393-1402, 2001.

[88] S. Ishikawa and K. Matsushima, "Aberrant B1 cell trafficking in a murine model for lupus," Frontiers in Bioscience, vol. 12, no. 5, pp. 1790-1803, 2007.

[89] P. Schaerli, K. Willimann, A. B. Lang, M. Lipp, P. Loetscher, and B. Moser, "CXC chemokine receptor 5 expression defines follicular homing T cells with B cell helper function," Journal of Experimental Medicine, vol. 192, no. 11, pp. 1553-1562, 2000.

[90] D. Breitfeld, L. Ohl, E. Kremmer et al., "Follicular B helper $\mathrm{T}$ cells express CXC chemokine receptor 5, localize to B cell follicles, and support immunoglobulin production," Journal of Experimental Medicine, vol. 192, no. 11, pp. 1545-1551, 2000.

[91] N. Fazilleau, L. Mark, L. J. McHeyzer-Williams, and M. G. McHeyzer-Williams, "Follicular Helper T cells: lineage and location,” Immunity, vol. 30, no. 3, pp. 324-335, 2009.

[92] C. G. Vinuesa, S. G. Tangye, B. Moser, and C. R. Mackay, "Follicular B helper T cells in antibody responses and autoimmunity," Nature Reviews Immunology, vol. 5, no. 11, pp. 853-865, 2005.

[93] C. K. Wong, P. T. Y. Wong, L. S. Tam, E. K. Li, D. P. Chen, and C. W. K. Lam, "Elevated production of B Cell Chemokine CXCL13 is correlated with systemic lupus erythematosus disease activity," Journal of Clinical Immunology, vol. 30, no. 1, pp. 45-52, 2010.

[94] L. Schiffer, P. Kümpers, A. M. Davalos-Misslitz et al., "B-cellattracting chemokine CXCL13 as a marker of disease activity and renal involvement in systemic lupus erythematosus (SLE)," Nephrology Dialysis Transplantation, vol. 24, no. 12, pp. 3708-3712, 2009.

[95] I. Rioja, F. J. Hughes, C. H. Sharp et al., "Potential novel biomarkers of disease activity in rheumatoid arthritis patients: CXCL13, CCL23, transforming growth factor $\alpha$, tumor necrosis factor receptor superfamily member 9, and macrophage colony-stimulating factor," Arthritis and Rheumatism, vol. 58, no. 8, pp. 2257-2267, 2008.

[96] P. Loetscher, M. Seitz, I. Clark-Lewis, M. Baggiolini, and B. Moser, "Monocyte chemotactic proteins MCP-1, MCP-2, and MCP-3 are major attractants for human $\mathrm{CD} 4^{+}$and $\mathrm{CD} 8^{+}$ T lymphocytes," FASEB Journal, vol. 8, no. 13, pp. 1055-1060, 1994.
[97] H. Nakajima, M. Kobayashi, R. B. Pollard, and F. Suzuki, "Monocyte chemoattractant protein-1 enhances HSV-induced encephalomyelitis by stimulating Th2 responses," Journal of Leukocyte Biology, vol. 70, no. 3, pp. 374-380, 2001.

[98] H. Kaneko, H. Ogasawara, T. Naito et al., "Circulating levels of $\beta$-chemokines in systemic lupus erythematosus," Journal of Rheumatology, vol. 26, no. 3, pp. 568-573, 1999.

[99] N. Iikuni, H. Okamoto, T. Yoshio et al., "Raised monocyte chemotactic protein-1 (MCP-1)/CCL2 in cerebrospinal fluid of patients with neuropsychiatric lupus," Annals of the Rheumatic Diseases, vol. 65, no. 2, pp. 253-256, 2006.

[100] T. J. Schall, K. Bacon, K. J. Toy, and D. V. Goeddel, "Selective attraction of monocytes and T lymphocytes of the memory phenotype by cytokine RANTES," Nature, vol. 347, no. 6294, pp. 669-671, 1990.

[101] L. C. W. Lit, C. K. Wong, L. S. Tam, E. K. M. Li, and C. W. K. Lam, "Raised plasma concentration and ex vivo production of inflammatory chemokines in patients with systemic lupus erythematosus," Annals of the Rheumatic Diseases, vol. 65, no. 2, pp. 209-215, 2006.

[102] X. Zhao, Y. Tang, B. Qu et al., "MicroRNA-125a contributes to elevated inflammatory chemokine RANTES levels via targeting KLF13 in systemic lupus erythematosus," Arthritis and Rheumatism, vol. 62, no. 11, pp. 3425-3435, 2010.

[103] V. Eis, B. Luckow, V. Vielhauer et al., "Chemokine receptor CCR1 but not CCR5 mediates leukocyte recruitment and subsequent renal fibrosis after unilateral ureteral obstruction," Journal of the American Society of Nephrology, vol. 15, no. 2, pp. 337-347, 2004.

[104] K. J. Moore, T. Wada, S. D. Barbee, and V. R. Kelley, "Gene transfer of RANTES elicits autoimmune renal injury in MRLFas ${ }^{l p r}$ mice," Kidney International, vol. 53, no. 6, pp. 16311641, 1998.

[105] R. W. Y. Chan, L. S. Tam, E. K. M. Li et al., "Inflammatory cytokine gene expression in the urinary sediment of patients with lupus nephritis," Arthritis and Rheumatism, vol. 48, no. 5, pp. 1326-1331, 2003.

[106] B. H. Rovin, H. Song, D. J. Birmingham, L. A. Hebert, C. Y. $\mathrm{Yu}$, and H. N. Nagaraja, "Urine chemokines as biomarkers of human systemic lupus erythematosus activity," Journal of the American Society of Nephrology, vol. 16, no. 2, pp. 467-473, 2005.

[107] M. Baggiolini, B. Dewald, and B. Moser, "Interleukin-8 and related chemotactic cytokines-CXC and CC chemokines," Advances in Immunology, vol. 55, pp. 97-179, 1994.

[108] E. Y. Lee, Z. H. Lee, and Y. W. Song, "CXCL10 and autoimmune diseases," Autoimmunity Reviews, vol. 8, no. 5, pp. 379383, 2009.

[109] S. Gasperini, M. Marchi, F. Calzetti et al., "Gene expression and production of the monokine induced by IFN- $\gamma$ (MIG), IFN-inducible T cell $\alpha$ chemoattractant (I-TAC), and IFN$\gamma$-inducible protein-10 (IP-10) chemokines by human neutrophils," Journal of Immunology, vol. 162, no. 8, pp. 49284937, 1999.

[110] S. Narumi, T. Takeuchi, Y. Kobayashi, and K. Konishi, "Serum levels of IFN-inducible protein-10 relating to the activity of systemic lupus erythematosus," Cytokine, vol. 12, no. 10, pp. 1561-1565, 2000.

[111] L. C. W. Lit, C. K. Wong, L. S. Tam, E. K. M. Li, and C. W. K. Lam, "Raised plasma concentration and ex vivo production of inflammatory chemokines in patients with systemic lupus erythematosus," Annals of the Rheumatic Diseases, vol. 65, no. 2, pp. 209-215, 2006. 
[112] H. Okamoto, N. Iikuni, S. Kamitsuji, T. Yoshio, S. Minota, and N. Kamatani, "IP-10/MCP-1 ratio in CSF is an useful diagnostic marker of neuropsychiatric lupus patients," Rheumatology, vol. 45, no. 2, pp. 232-234, 2006.

[113] H. Okamoto, Y. Katsumata, K. Nishimura, and N. Kamatani, "Interferon-inducible protein 10/CXCL10 is increased in the cerebrospinal fluid of patients with central nervous system lupus," Arthritis and Rheumatism, vol. 50, no. 11, pp. 37313732, 2004.

[114] T. Matsumiya, T. Imaizumi, H. Itaya et al., "Production of growth related oncogene protein- $\alpha$ in human umbilical vein endothelial cells stimulated with soluble interleukin-6 receptor- $\alpha$ : role of signal transducers, janus kinase 2 and mitogen-activated kinase kinase," Life Sciences, vol. 70, no. 26, pp. 3179-3190, 2002.

[115] P. Pantelidis, A. M. Southcott, C. M. Black, and R. M. Du Bois, "Up-regulation of IL-8 secretion by alveolar macrophages from patients with fibrosing alveolitis: a subpopulation analysis," Clinical and Experimental Immunology, vol. 108, no. 1, pp. 95-104, 1997.

[116] M. B. Bolster, A. Ludwicka, S. E. Sutherland, C. Strange, and R. M. Silver, "Cytokine concentrations in bronchoalveolar lavage fluid of patients with systemic sclerosis," Arthritis and Rheumatism, vol. 40, no. 4, pp. 743-751, 1997.

[117] C. K. Wong, W. K. Ip, and C. W. K. Lam, "Biochemical assessment of intracellular signal transduction pathways in eosinophils: implications for pharmacotherapy," Critical Reviews in Clinical Laboratory Sciences, vol. 41, no. 1, pp. 79-113, 2004.

[118] L. Chang and M. Karin, "Mammalian MAP kinase signalling cascades," Nature, vol. 410, no. 6824, pp. 37-40, 2001.

[119] P. F. Y. Cheung, C. K. Wong, W. K. Ip, and C. W. K. Lam, "IL-25 regulates the expression of adhesion molecules on eosinophils: mechanism of eosinophilia in allergic inflammation," Allergy, vol. 61, no. 7, pp. 878-885, 2006.

[120] C. K. Wong, P. F. Y. Cheung, W. K. Ip, and C. W. K. Lam, "Interleukin-25-induced chemokines and interleukin-6 release from eosinophils is mediated by p 38 mitogen-activated protein kinase, c-Jun $\mathrm{N}$-terminal kinase, and nuclear factor- $\kappa \mathrm{B}$," American Journal of Respiratory Cell and Molecular Biology, vol. 33, no. 2, pp. 186-194, 2005.

[121] C. K. Wong, P. W. Li, and C. W. K. Lam, "Intracellular JNK, p38 MAPK and NF- $\kappa$ B regulate IL-25 induced release of cytokines and chemokines from costimulated T helper lymphocytes," Immunology Letters, vol. 112, no. 2, pp. 82-91, 2007.

[122] G. A. Bishop, Y. Hsing, B. S. Hostager, S. V. Jalukar, L. M. Ramirez, and M. A. Tomai, "Molecular mechanisms of B lymphocyte activation by the immune response modifier R848," Journal of Immunology, vol. 165, no. 10, pp. 5552-5557, 2000.

[123] K. Yoshimoto, Y. Takahashi, M. Ogasawara et al., "Aberrant expression of BAFF in T cells of systemic lupus erythematosus, which is recapitulated by a human T cell line, Loucy," International Immunology, vol. 18, no. 7, pp. 1189-1196, 2006.

[124] S. L. Peng, A. J. Gerth, A. M. Ranger, and L. H. Glimcher, "NFATc1 and NFATc2 together control both T and B cell activation and differentiation," Immunity, vol. 14, no. 1, pp. 13-20, 2001.

[125] F. Pessler, L. Dai, R. Q. Cron, and H. R. Schumacher, "NFAT transcription factors - New players in the pathogenesis of inflammatory arthropathies?" Autoimmunity Reviews, vol. 5, no. 2, pp. 106-110, 2006.

[126] H. K. Wong, G. M. Kammer, G. Dennis, and G. C. Tsokos, "Abnormal NF- $\kappa \mathrm{B}$ activity in T lymphocytes from patients with systemic lupus erythematosus is associated with decreased p65-RelA protein expression," Journal of Immunology, vol. 163, no. 3, pp. 1682-1689, 1999.

[127] S. Gorjestani, V. Rider, B. F. Kimler, C. Greenwell, and N. I. Abdou, "Extracellular signal-regulated kinase 1/2 signalling in SLE T cells is influenced by oestrogen and disease activity," Lupus, vol. 17, no. 6, pp. 548-554, 2008.

[128] S. N. C. Liossis, E. E. Solomou, M. A. Dimopoulos, P. Panayiotidis, M. M. Mavrikakis, and P. P. Sfikakis, "Bcell kinase lyn deficiency in patients with systemic lupus erythematosus," Journal of Investigative Medicine, vol. 49, no. 2, pp. 157-165, 2001.

[129] E. C. Jury, P. S. Kabouridis, A. Abba, R. A. Mageed, and D. A. Isenberg, "Increased ubiquitination and reduced expression of LCK in T lymphocytes from patients with systemic lupus erythematosus," Arthritis and Rheumatism, vol. 48, no. 5, pp. 1343-1354, 2003.

[130] C. Deng, M. J. Kaplan, J. Yang et al., "Decreased rasmitogen-activated protein kinase signaling may cause DNA hypomethylation in T lymphocytes from lupus patients," Arthritis and Rheumatism, vol. 44, no. 2, pp. 397-407, 2001.

[131] C. K. Wong, P. T. Y. Wong, L. S. Tam, E. K. Li, D. P. Chen, and C. W. K. Lam, "Activation profile of intracellular mitogen-activated protein kinases in peripheral lymphocytes of patients with systemic lupus erythematosus," Journal of Clinical Immunology, vol. 29, no. 6, pp. 738-746, 2009.

[132] R. Verdolini, L. Bugatti, M. Giangiacomi, M. Nicolini, G. Filosa, and R. Cerio, "Systemic lupus erythematosus induced by Epstein-Barr virus infection," British Journal of Dermatology, vol. 146, no. 5, pp. 877-881, 2002.

[133] H. Tomita, M. Yamada, I. Sekigawa, T. Yoshiike, N. Iida, and H. Hashimoto, "Systemic lupus erythematosus-like autoimmune abnormalities induced by bacterial infection," Clinical and Experimental Rheumatology, vol. 21, no. 4, pp. 497-499, 2003.

[134] M. R. Lerner, N. C. Andrews, G. Miller, and J. A. Steitz, "Two small RNAs encoded by Epstein-Barr virus and complexed with protein are precipitated by antibodies from patients with systemic lupus erythematosus," Proceedings of the $\mathrm{Na}$ tional Academy of Sciences of the United States of America, vol. 78, no. 2, pp. 805-809, 1981.

[135] T. Kawai and S. Akira, "Innate immune recognition of viral infection," Nature Immunology, vol. 7, no. 2, pp. 131-137, 2006.

[136] D. Werling and T. W. Jungi, "TOLL-like receptors linking innate and adaptive immune response," Veterinary Immunology and Immunopathology, vol. 91, no. 1, pp. 1-12, 2003.

[137] M. Yamamoto, S. Sato, H. Hemmi et al., "Role of adaptor TRIF in the MyD88-independent toll-like receptor signaling pathway," Science, vol. 301, no. 5633, pp. 640-643, 2003.

[138] M. Fischer and M. Ehlers, "Toll-like receptors in autoimmunity," Annals of the New York Academy of Sciences, vol. 1143, pp. 21-34, 2008.

[139] L. A. J. O’Neill, “The interleukin-1 receptor/Toll-like receptor superfamily: 10 Years of progress," Immunological Reviews, vol. 226, no. 1, pp. 10-18, 2008.

[140] K. Takeda, T. Kaisho, and S. Akira, “Toll-like receptors," Annual Review of Immunology, vol. 21, pp. 335-376, 2003.

[141] A. Sadanaga, H. Nakashima, M. Akahoshi et al., "Protection against autoimmune nephritis in MyD88-deficient MRL/lpr mice," Arthritis and Rheumatism, vol. 56, no. 5, pp. 16181628, 2007.

[142] R. D. Pawar, A. Ramanjaneyulu, O. P. Kulkarni, M. Lech, S. Segerer, and H. J. Anders, "Inhibition of Toll-like receptor-7 
(TLR-7) or TLR-7 plus TLR-9 attenuates glomerulonephritis and lung injury in experimental lupus," Journal of the American Society of Nephrology, vol. 18, no. 6, pp. 1721-1731, 2007.

[143] S. R. Christensen, J. Shupe, K. Nickerson, M. Kashgarian, R. Flavell, and M. J. Shlomchik, "Toll-like receptor 7 and TLR9 dictate autoantibody specificity and have opposing inflammatory and regulatory roles in a murine model of lupus," Immunity, vol. 25, no. 3, pp. 417-428, 2006.

[144] M. Ehlers, H. Fukuyama, T. L. McGaha, A. Aderem, and J. V. Ravetch, "TLR9/MyD88 signaling is required for class switching to pathogenic IgG2a and 2b autoantibodies in SLE," Journal of Experimental Medicine, vol. 203, no. 3, pp. 553-561, 2006.

[145] H. Poeck, M. Wagner, J. Battiany et al., "Plasmacytoid dendritic cells, antigen, and CpG-C license human B cells for plasma cell differentiation and immunoglobulin production in the absence of T-cell help," Blood, vol. 103, no. 8, pp. 30583064, 2004.

[146] E. D. Papadimitraki, C. Choulaki, E. Koutala et al., "Expansion of toll-like receptor 9-expressing B cells in active systemic lupus erythematosus: implications for the induction and maintenance of the autoimmune process," Arthritis and Rheumatism, vol. 54, no. 11, pp. 3601-3611, 2006.

[147] A. Komatsuda, H. Wakui, K. Iwamoto et al., "Up-regulated expression of Toll-like receptors mRNAs in peripheral blood mononuclear cells from patients with systemic lupus erythematosus," Clinical and Experimental Immunology, vol. 152, no. 3, pp. 482-487, 2008.

[148] C. K. Wong, P. T. Wong, L. S. Tam, E. K. Li, D. P. Chen, and C. W. Lam, "Activation profile of Toll-like receptors of peripheral blood lymphocytes in patients with systemic lupus erythematosus," Clinical and Experimental Immunology, vol. 159, no. 1, pp. 11-22, 2010.

[149] P. K. C. S. L. Yu, C. K. Wong, C. C. Szeto, and S. C. Ho, "Antagonist-mediated down-regulation of the expression of intracellular toll-like receptors increases the prevalence of human papillomavirus infection in systemic lupus erythematosus. Abstract of the European league against rheumatism annual congress," Annals of the Rheumatic Diseases, vol. 70, supplement 3, p. 529, 2011.

[150] N. Inohara, M. Chamaillard, C. McDonald, and G. Nuñez, "NOD-LRR proteins: role in host-microbial interactions and inflammatory disease," Annual Review of Biochemistry, vol. 74, pp. 355-383, 2005.

[151] T. A. Kufer, J. H. Fritz, and D. J. Philpott, "NACHT-LRR proteins (NLRs) in bacterial infection and immunity," Trends in Microbiology, vol. 13, no. 8, pp. 381-388, 2005.

[152] D. V. Koval'chuk, M. V. Khoreva, and A. S. Nikonova, "Recognition receptors of innate immunity (NLR, RLr, and CLR)," Zhurnal Mikrobiologii, Epidemiologii, i Immunobiologii, no. 1, pp. 93-100, 2011.

[153] M. Fukata, A. S. Vamadevan, and M. T. Abreu, "Toll-like receptors (TLRs) and Nod-like receptors (NLRs) in inflammatory disorders," Seminars in Immunology, vol. 21, no. 4, pp. 242-253, 2009.

[154] T. D. Kanneganti, M. Lamkanfi, and G. Núñez, "Intracellular NOD-like receptors in host defense and disease," Immunity, vol. 27, no. 4, pp. 549-559, 2007.

[155] C. Ospelt, F. Brentano, A. Jüngel et al., "Expression, regulation, and signaling of the pattern-recognition receptor nucleotide-binding oligomerization domain 2 in rheumatoid arthritis synovial fibroblasts," Arthritis and Rheumatism, vol. 60, no. 2, pp. 355-363, 2009.
[156] L. A. B. Joosten, B. Heinhuis, S. Abdollahi-Roodsaz et al., "Differential function of the NACHT-LRR (NLR) members Nod1 and Nod2 in arthritis," Proceedings of the National Academy of Sciences of the United States of America, vol. 105, no. 26, pp. 9017-9022, 2008.

[157] W. Strober, P. J. Murray, A. Kitani, and T. Watanabe, "Signalling pathways and molecular interactions of NOD1 and NOD2," Nature Reviews Immunology, vol. 6, no. 1, pp. 9-20, 2006.

[158] I. Ferreiros-Vidal, J. Garcia-Meijide, P. Carreira et al., "The three most common CARD15 mutations associated with Crohn's disease and the chromosome 16 susceptibility locus for systemic lupus erythematosus," Rheumatology, vol. 42, no. 4, pp. 570-574, 2003.

[159] O. Hitotsumatsu, R. C. Ahmad, R. Tavares et al., "The ubiquitin-editing enzyme A20 restricts nucleotide-binding oligomerization domain containing 2-triggered signals," Immunity, vol. 28, no. 3, pp. 381-390, 2008.

[160] R. R. Graham, C. Cotsapas, L. Davies et al., "Genetic variants near TNFAIP3 on $6 \mathrm{q} 23$ are associated with systemic lupus erythematosus," Nature Genetics, vol. 40, no. 9, pp. 10591061,2008

[161] S. L. Musone, K. E. Taylor, T. T. Lu et al., "Multiple polymorphisms in the TNFAIP3 region are independently associated with systemic lupus erythematosus," Nature Genetics, vol. 40, no. 9, pp. 1062-1064, 2008.

[162] J. W. Han, H. F. Zheng, Y. Cui et al., "Genome-wide association study in a Chinese Han population identifies nine new susceptibility loci for systemic lupus erythematosus," Nature Genetics, vol. 41, no. 11, pp. 1234-1237, 2009.

[163] I. Adrianto, F. Wen, A. Templeton et al., "Association of a functional variant downstream of TNFAIP3 with systemic lupus erythematosus," Nature Genetics, vol. 43, no. 3, pp. 253-258, 2011.

[164] A. J. van Beelen, Z. Zelinkova, E. W. Taanman-Kueter et al., "Stimulation of the intracellular bacterial sensor NOD2 programs dendritic cells to promote interleukin-17 production in human memory T cells," Immunity, vol. 27, no. 4, pp. 660669, 2007.

[165] S. L. Yu, C. K. Wong, P. T. Wong et al., "Down-regulated NOD2 by immunosuppressants in peripheral blood cells in patients with SLE reduces the muramyl dipeptide-induced IL-10 production," PLoS One, vol. 6, no. 8, Article ID e23855, 2011.

[166] L. S. Tam, P. K. S. Chan, S. C. Ho et al., "Risk factors for squamous intraepithelial lesions in systemic lupus erythematosus: a prospective cohort study," Arthritis Care and Research, vol. 63, no. 2, pp. 269-276, 2011.

[167] L. S. Tam, E. K. Li, S. M. Wong, and C. C. Szeto, "Risk factors and clinical features for tuberculosis among patients with systemic lupus erythematosus in Hong Kong," Scandinavian Journal of Rheumatology, vol. 31, no. 5, pp. 296-300, 2002.

[168] L. S. Tam, A. Y. Chan, P. K. Chan, A. R. Chang, and E. K. $\mathrm{Li}$, "Increased prevalence of squamous intraepithelial lesions in systemic lupus erythematosus: association with human papillomavirus infection," Arthritis and Rheumatism, vol. 50, no. 11, pp. 3619-3625, 2004.

[169] L. S. Tam, P. K. S. Chan, S. C. Ho et al., "Natural history of cervical papilloma virus infection in systemic lupus erythematosus - a prospective cohort study," Journal of Rheumatology, vol. 37, no. 2, pp. 330-340, 2010.

[170] S. E. Sweeney and G. S. Firestein, "Signal transduction in rheumatoid arthritis," Current Opinion in Rheumatology, vol. 16, no. 3, pp. 231-237, 2004. 
[171] M. J. Thiel, C. J. Schaefer, M. E. Lesch et al., "Central role of the MEK/ERK MAP kinase pathway in a mouse model of rheumatoid arthritis: potential proinflammatory mechanisms," Arthritis and Rheumatism, vol. 56, no. 10, pp. 3347-3357, 2007.

[172] J. A. Bubier, S. M. Bennett, T. J. Sproule et al., "Treatment of BXSB-Yaa mice with IL-21R-Fc fusion protein minimally attenuates systemic lupus erythematosus," Annals of the New York Academy of Sciences, vol. 1110, pp. 590-601, 2007.

[173] B. Zheng, Z. Ozen, X. Zhang et al., "CXCL13 neutralization reduces the severity of collagen-induced arthritis," Arthritis and Rheumatism, vol. 52, no. 2, pp. 620-626, 2005.

[174] W. U. Kim, A. Sreih, and R. Bucala, "Toll-like receptors in systemic lupus erythematosus; prospects for therapeutic intervention," Autoimmunity Reviews, vol. 8, no. 3, pp. 204-208, 2009.

[175] F. J. Barrat and R. L. Coffman, "Development of TLR inhibitors for the treatment of autoimmune diseases," Immunological Reviews, vol. 223, no. 1, pp. 271-283, 2008. 


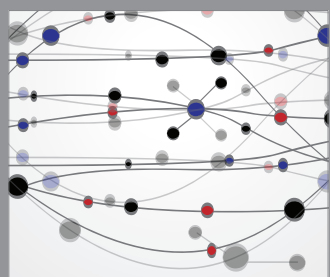

The Scientific World Journal
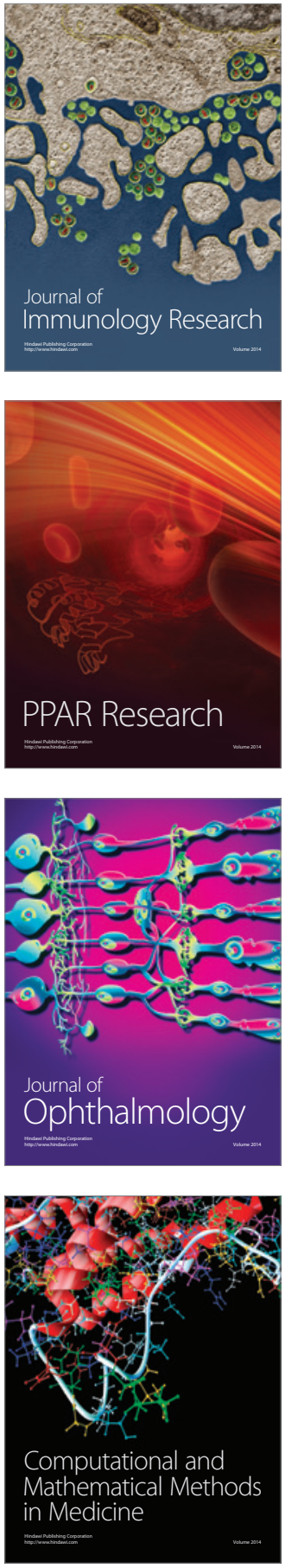

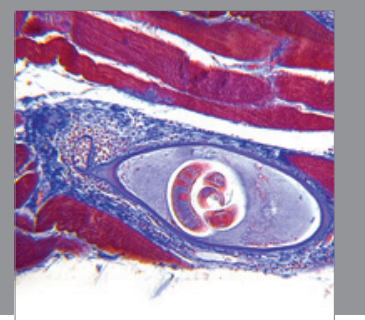

Gastroenterology

Research and Practice
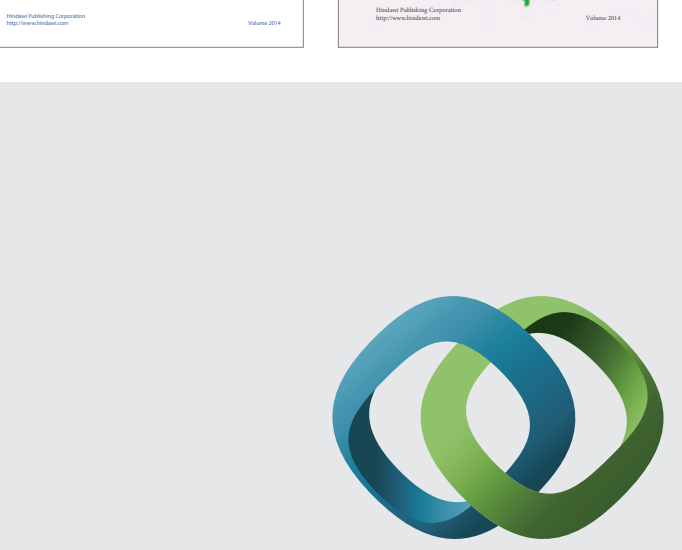

\section{Hindawi}

Submit your manuscripts at

http://www.hindawi.com
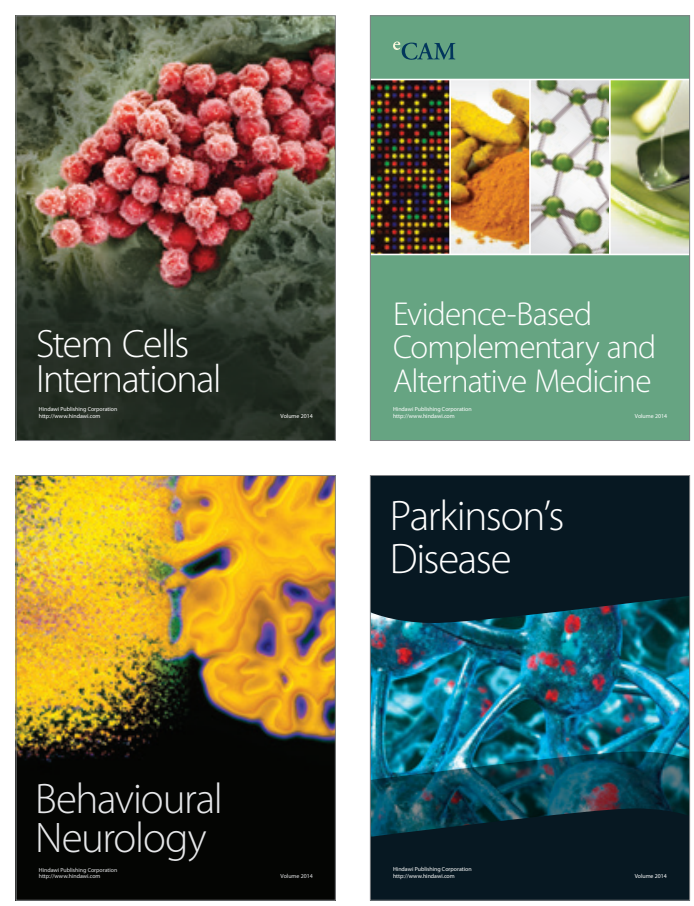

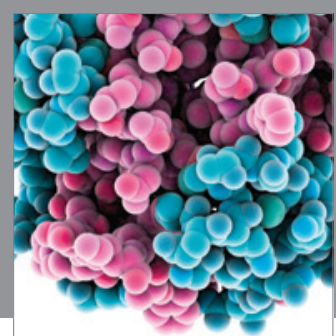

Journal of
Diabetes Research

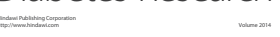

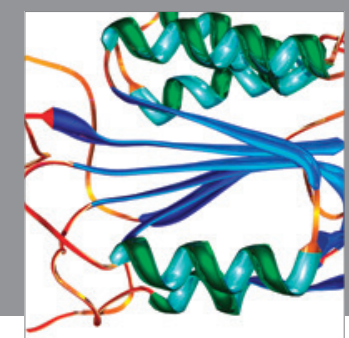

Disease Markers
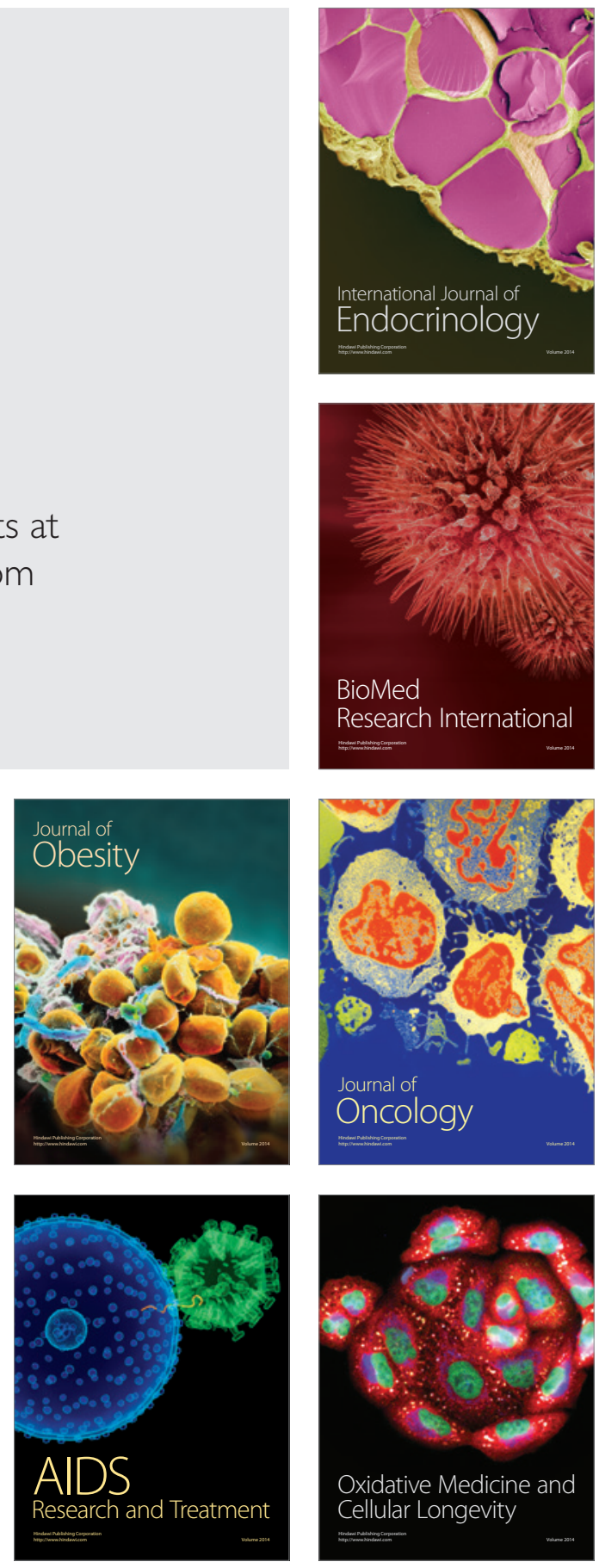